\title{
(6) OPEN ACCESS \\ The association between job strain and atrial fibrillation in Swedish men
}

\author{
Kjell Torén, ${ }^{1,2}$ Linus Schiöler, ${ }^{1}$ Mia Söderberg, ${ }^{1}$ Kok Wai Giang, ${ }^{3}$ Annika Rosengren ${ }^{3}$
}

\begin{abstract}
${ }^{1}$ Section of Occupational and Environmental Medicine, Institute of Medicine, Sahlgrenska Academy University of Gothenburg, Gothenburg, Sweden ${ }^{2}$ Department of Occupational Medicine, Respiratory Diseases and Toxicology, University of Perugia, Italy

${ }^{3}$ Department of Molecular and Clinical Medicine, Institute of Medicine, Sahlgrenska Academy, University of Gothenburg, Gothenburg, Sweden
\end{abstract}

\section{Correspondence to} Professor Kjell Torén, Section of Occupational and Environmental Medicine, University of Gothenburg, Box 414, Gothenburg S-405 30, Sweden; Kjell.Toren@amm.gu.se

Received 4 April 2014 Revised 13 October 2014 Accepted 21 October 2014 Published Online First 18 December 2014

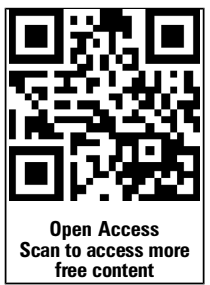

\section{ABSTRACT}

Objectives The purpose of this study was to investigate whether psychosocial stress defined as high strain based on the job demand-control model increases risk for atrial fibrillation.

Methods The present study comprised 6035 men born between 1915 and 1925 and free from previous coronary heart disease, atrial fibrillation and stroke at baseline (1974-1977). Work-related psychosocial stress was measured using a job-exposure matrix for the job demand-control model based on occupation at baseline. The participants were followed from baseline examination until death, hospital discharge or 75 years of age, using the Swedish national register on cause of death and the Swedish hospital discharge register for any registration for atrial fibrillation, resulting in the identification of 436 cases. Data were analysed with Cox regression models with atrial fibrillation as the outcome using high strain as the explanatory variable adjusted for age, smoking, body mass index, hypertension, diabetes and socioeconomic status.

Results There was an increased risk for atrial fibrillation in relation to high strain (HR 1.32, 95\% Cl 1.003 to 1.75). When the four categories of the job-strain model were included and low strain was used as reference, the risk for high strain decreased (HR 1.23, 95\% Cl 0.84 to 1.82). Conclusions Exposure to occupational psychosocial stress defined as high strain may be associated with increased risk for atrial fibrillation. The observed increase in risk is small and residual confounding may also be present.

\section{INTRODUCTION}

Exposure to psychosocial stress in the workplace is associated with increased risk for conditions such as coronary heart disease and depression. ${ }^{12}$ The job demand-control model has been used most to study work place-related stress. ${ }^{3}$ In this model, the combination of high demands and low decision latitude at work, high strain, was postulated to be a risk factor for cardiovascular disease. Many studies demonstrate that high strain is associated with an increased risk of coronary heart disease. ${ }^{14}$

Atrial fibrillation is the most common cardiac arrhythmia, with the life-time risk shown to be about one in four in a US population. ${ }^{5}$ Atrial fibrillation is associated with significant morbidity and mortality, including a four- to fivefold increased risk for stroke, and a significant risk for premature mortality. ${ }^{67}$ Many potential modifiable risk factors for atrial fibrillation have been described. ${ }^{8} 9$ Previous studies have concluded that hypertension, large body size and, to some extent, smoking

\section{What this paper adds}

Men with high strain may have an increased risk for atrial fibrillation.

- The observed risk is small and residual confounding may be present.

- This is the first longitudinal general population-based study in this field.

increase the risk for atrial fibrillation. ${ }^{10}$ However, psychosocial factors so far have received little attention, particularly the evidence linking exposure to psychosocial stress in the workplace and atrial fibrillation. In the Framingham Offspring Study, a prospective analysis showed that symptoms of anger and hostility at baseline were associated with an increased risk of developing atrial fibrillation, mainly among men. ${ }^{11} 12$ To the best of our knowledge there are no longitudinal general population studies analysing the impact of psychosocial stress at work and the risk of atrial fibrillation.

The aim of the present analyses was to investigate whether psychosocial stress based on the job demand-control model increased the risk for atrial fibrillation, based on a longitudinal general population-based study of 6035 Swedish men.

\section{METHODS}

\section{Study population}

The Primary Prevention Study (PPS) is a population-based cohort study from Gothenburg, Sweden. ${ }^{13}$ The initial study population was a random sample of 10000 men born between 1915 and 1925. Of those, 7494 men $(75 \%$ of the sample) participated in screening examinations between January 1970 and March $1973 .{ }^{9}{ }^{14}$ Three years later, in 1974-1977, a follow-up investigation involving 7133 men was carried out. In the present study we used data from the follow-up investigation, because there were complete occupational data from this follow-up. All participants gave their informed consent to participate in the study and it was approved by the Ethics Committee for Medical Research at Gothenburg University.

Occupation at baseline (1974-1977) was classified at three-digit level according to the Nordic Classification of Occupations, NYK-74. ${ }^{15}$ For assessing psychosocial workplace exposure, we used a previously published job-exposure matrix (JEM). ${ }^{16} 17$ This JEM was developed in the late 1970 s based on information from large Swedish population surveys where around 12000 randomly 
selected subjects aged 25-74 years were classified according to psychological demands and decision latitude. The JEM provides separate estimates of demand and control for 261 occupations separated into gender and age (25-44 and 45-74).

Psychological job demands were explored with four items and decision latitude was explored with seven items. All items were scored using a scale, ${ }^{1-10}$ with a score of 10 indicating high psychological demands or high decision latitude, respectively. Each subject was assigned a score based on occupation and age. The scores were then dichotomised into high and low, using the median of the distribution as cut-off. Combining demand and control with the median cut-offs divides the participants into four categorical quadrants: high strain (high demand-low control), active (high demand-high control), passive (low demand-low control) and low strain (low demand-high control).

At baseline, information was collected about age, country of birth (Sweden/other), body mass index (BMI), systolic blood pressure, diastolic blood pressure, use of antihypertensive medication (yes/no), history of diabetes (yes/no), coronary heart disease (yes/no), atrial fibrillation (yes/no), stroke (yes/no), smoking and socioeconomic status (white collar or blue collar worker) as previously described. ${ }^{14} 18$ Hypertension was defined as systolic blood pressure $>140 \mathrm{~mm} \mathrm{Hg}$ or diastolic blood pressure $>90 \mathrm{~mm} \mathrm{Hg}$ or receiving antihypertensive treatment. An ECG was registered.

Based on unique personal identification numbers, the subjects were matched with the Swedish national register on cause of death and the Swedish hospital discharge register. The hospital discharge register has operated on a nationwide basis since 1987, while all discharges from Gothenburg hospitals have been entered in the national register since 1970 (except for 1976, because of a legislative change for that year). The International Classification of Disease (ICD) codes listed in the registries were used to identify events with atrial fibrillation (both non-fatal and fatal events) during the entire follow-up period. The eighth version of the ICD code was used until 1986, ICD-9 was used from 1987 to 1996, and ICD-10 was used from 1997 onwards. Atrial fibrillation was defined as ICD codes 427.92, 427D or I48.

Subjects with a history of coronary heart disease or stroke at baseline were excluded, as were men with a previous hospitalisation discharge code of atrial fibrillation or an ECG showing atrial fibrillation, resulting in a study population of 6035 subjects (table 1).

\section{Statistical analysis}

Descriptive statistics are presented as percentages or mean values with SDs. The SAS statistical package (V.9.3) was used for most of the analyses. The data were analysed with Cox regression models using SAS (PROC PHREG). The proportional hazards assumptions were investigated using tests based on cumulative sums of martingale residuals, ${ }^{19}$ and were found reasonable for all models. Hospital care or death (whichever came first) from atrial fibrillation were events and time was measured as months since baseline. Subjects dying of other causes were censored at the time of death. The observation period stopped at the age of 75 , but a separate analyses was performed for age $<65$ years. In the full model, HRs were calculated using high strain based on the job demand-control model with adjustments for age, smoking, BMI, hypertension, diabetes and socioeconomic status at baseline. There was also one model with 5 years of latency time, that is, excluding subject with any event occurring during the first 5 years during follow-up. Smoking was categorised as never-smoking, former smoking, starter during follow-up, current smoking and unknown smoking
Table 1 Descriptive data of the population

\begin{tabular}{lccc}
\hline & High strain & Other & Overall \\
\hline $\mathrm{N}(\%)$ & $668(11.1)$ & $5367(88.9)$ & $6035(100)$ \\
Age, years & $55.3(2.0)$ & $55.3(2.1)$ & $55.3(2.1)$ \\
Cholesterol & $6.45(0.9)$ & $6.40(1.04)$ & $6.40(1.05)$ \\
Systolic blood pressure, mm Hg & $147.2(20.5)$ & $145.9(19.5)$ & $146.0(19.6)$ \\
Body mass index & $25.6(3.3)$ & $25.7(3.2)$ & $25.6(3.7)$ \\
Diabetes, \% (n) & $3.6(24)$ & $2.7(144)$ & $2.8(168)$ \\
Hypertension, \% (n) & $23.5(157)$ & $21.8(1171)$ & $22.7(1328)$ \\
Hypertensive medication, \% (n) & $16.3(109)$ & $14.5(777)$ & $14.7(886)$ \\
White collar job, \% (n) & $26.3(178)$ & $53.2(2855)$ & $50.2(3033)$ \\
Self-reported stress at baseline, \% & $36.3(234)$ & $36.7(1925)$ & $36.7(2159)$ \\
Smoking status, \% (n) & & & \\
$\quad$ Never & $21.1(141)$ & $24.0(1289)$ & $23.7(1430)$ \\
$\quad$ Current & $44.8(299)$ & $36.8(1973)$ & $37.6(2272)$ \\
Quitter & $26.8(179)$ & $31.7(1700)$ & $31.1(1879)$ \\
$\quad$ Starter & $2.7(18)$ & $2.9(154)$ & $2.9(172)$ \\
$\quad$ Unknown & $4.6(31)$ & $4.7(251)$ & $4.7(282)$ \\
Number (\%) of events & $60(9.0)$ & $376(7.0)$ & $436(7.2)$ \\
Age at event & $68.2(5.2)$ & $68.5(4.9)$ & $68.5(4.9)$ \\
Follow-up time, years & $16.5(4.9)$ & $16.9(4.8)$ & $16.8(4.8)$ \\
\hline Values are mean (SD) unless otherwise noted. & & \\
& & &
\end{tabular}

habits. There was also one model using all four categories of the job-strain model using low strain as the reference category, as well as models with demand and control as continuous variables. In the model with the continuous variables, the interaction between demand and control was tested using a multiplicative term included as a covariate. ${ }^{20}$

\section{RESULTS}

Over the follow-up period, there were 436 events due to atrial fibrillation (table 1). Among all subjects, $11.1 \%$ were classified as exposed to high strain, with $13.8 \%$ of those with atrial fibrillation classified as exposed to high strain. In a fully adjusted model, there was an increased risk for atrial fibrillation in relation to high strain (HR 1.32, 95\% CI 1.003 to 1.75) (table 2). There was also an increased risk for atrial fibrillation among

Table 2 HRs of atrial fibrillation in relation to work-related psychosocial stress in a longitudinal general population-based study of 6070 Swedish men

\begin{tabular}{|c|c|c|}
\hline Variable & HR & $95 \% \mathrm{Cl}$ \\
\hline High strain* & 1.32 & 1.003 to 1.75 \\
\hline Current smokingt & 1.15 & 0.90 to 1.45 \\
\hline Former smokingt & 1.18 & 0.92 to 1.51 \\
\hline Startert & 0.68 & 0.33 to 1.40 \\
\hline Unknownt & 0.82 & 0.49 to 1.39 \\
\hline Blue collarł & 1.02 & 0.84 to 1.24 \\
\hline Hypertension‡ & 1.56 & 1.26 to 1.93 \\
\hline Body mass index§ & 1.04 & 1.01 to 1.07 \\
\hline Diabetes $\ddagger$ & 1.30 & 0.74 to 2.27 \\
\hline \multicolumn{3}{|c|}{$\begin{array}{l}\text { The results are from the } \\
\text { status, hypertension, bod } \\
\text { *Versus others. } \\
\text { †Versus never smoking. } \\
\ddagger \text { Yes versus no. } \\
\text { §er unit }\left(\mathrm{kg} / \mathrm{m}^{2}\right) \text {. }\end{array}$} \\
\hline
\end{tabular}


Table 3 HRs of atrial fibrillation in relation to low strain according to the four categories of the job strain model (high strain, active, passive and low strain) in a longitudinal general population-based study of 6070 Swedish men

\begin{tabular}{lll}
\hline & Demands & \\
\cline { 2 - 3 } Control & High & Low \\
\hline High & Active & Low strain \\
\multirow{2}{*}{ Low } & HR $1.19(0.81$ to 1.77$)$ & 1.0 \\
& High strain & Passive \\
& HR 1.23 (0.84 to 1.82) & HR $0.87(0.63$ to 1.22) \\
\hline
\end{tabular}

All models are adjusted for age, smoking, socioeconomic status, hypertension, body mass index and diabetes. Demand and control is dichotomised by the median.

those with hypertension, and BMI was positively associated with an increased risk for atrial fibrillation (table 2).

When age until follow-up was restricted to 65 years, relative risks were similar but due to lack of power all estimates were without statistical significance. The overall estimate was 1.32 (95\% CI 0.71 to 2.28$)$. In the additional analyses in subjects with 5 years of latency time, the results were similar as the risk for atrial fibrillation among subjects with high strain was 1.29 (95\% CI 0.95 to 1.71 ).

In fully adjusted models with the four categories of the jobstrain model, there were no significant findings when low strain was used as the reference category (table 3 ). The highest risk was among those with high strain (HR 1.23, 95\% CI 0.84 to 1.82). When modelling demands and control as continuous variables, there were no statistically significant results for either decreasing control (HR 1.01, 95\% CI 0.93 to 1.10) or increasing demands (HR $0.98,95 \%$ CI 0.83 to 1.67). The multiplicative interaction term was not statistically significant $(p=0.43)$.

The five most common occupations in the high strain group were local transport drivers (19.2\%), bus drivers (14.3\%), primary education teachers $(6.3 \%)$, dockers and freight handlers $(5.1 \%)$ and bakers $(4.3 \%)$.

\section{DISCUSSION}

In this study we found that exposure to high strain was associated with an increased risk for atrial fibrillation. The risk estimates were only moderately increased, and not statistically significant in the full multivariable analysis. Additionally, residual confounding by unknown factors that we did not measure has to be considered.

However, this study has several methodological strengths, including a general population design with a long follow-up and use of a national mortality register and hospital discharge register with high coverage. Work-related psychosocial stress was estimated using the reported occupations. Such information is probably less biased than self-reports of demand and control. One important limitation, however, is that the assessment of work-related psychosocial stress was measured only once, at baseline. However, the subjects studied were in their 50s at baseline, indicating that they were probably relatively stable in their occupations. One further limitation is that the study consisted only of men, which limits the external validity. In the study, the risk associated with high strain was analysed in relation to all other subjects. In previous analysis, all job demand-control quadrants were studied. ${ }^{14}$ However, in the present study, due to fewer cases, there was insufficient power to use all four quadrants in the analyses.
The mechanisms behind atrial fibrillation include inflammation, structural remodelling of the atrium and atrial fibrosis. ${ }^{21}$ Such processes will be clinically silent for a number of years. The subjects in the present study were followed until 75 years of age with one subanalysis censored at age 65 . The risk estimates were similar in both approaches, indicating that the increased risk is also present after the subjects have stopped working. Some subjects may have retired before 65 years of age, but we do not have access to that information.

The results from the present study indicate that work-related psychosocial stress defined as high strain may be associated with increased risk for atrial fibrillation. However, the risks are small and residual confounding may be present. Hence, this finding should be confirmed in further studies, as we have not identified any general population-based study reporting this observation. There is probably a publication bias as studies with no or weak associations may have not be published, as has been shown for job strain and coronary heart disease. ${ }^{22}$ This study reflects exposure conditions in the last 30 years, but is probably also relevant for current conditions. The most common occupations in our study classified as having high strain were lorry drivers, bus drivers, freight handlers, bakers and teachers. Professional driving has long been linked to cardiovascular diseases such as stroke and coronary heart disease. ${ }^{23}$

Some studies have shown an increased risk for atrial fibrillation associated with long-term practice of endurance sports, and it has been speculated that this is related to a chronic volume and pressure overload caused by increased physical activity. ${ }^{24-26}$ One may speculate that long-term psychosocial stress (high strain) may cause similar effects. However, the present finding has to be confirmed in future longitudinal studies.

\section{CONCLUSIONS}

Exposure to occupational psychosocial stress defined as high strain may be associated with increased risk for atrial fibrillation. The observed increase in risk is small and residual confounding may be present.

Contributors All authors were responsible for the design, for drafting the manuscript and for final approval of the manuscript. In addition, LS performed the statistical analyses.

Funding The study was funded by the Swedish Research Council (VR), the Swedish Research Council for Health, Working Life and Welfare (Forte) and the Swedish Heart and Lung Foundation.

\section{Competing interests None.}

Ethics approval The Ethics Committee for Medical Research at the University of Gothenburg approved this study.

Provenance and peer review Not commissioned; externally peer reviewed.

Open Access This is an Open Access article distributed in accordance with the Creative Commons Attribution Non Commercial (CC BY-NC 4.0) license, which permits others to distribute, remix, adapt, build upon this work non-commercially, and license their derivative works on different terms, provided the original work is properly cited and the use is non-commercial. See: http://creativecommons.org/ licenses/by-nc/4.0/

\section{REFERENCES}

1 Kuper $H$, Marmot M, Hemingway $H$. Systematic review of prospective cohort studies of psychosocial factors in the etiology and prognosis of coronary heart disease. Semin Vasc Med 2002;2:266-314.

2 Bonde JPE. Psychosocial factors at work and risk of depression: a systematic review of epidemiological evidence. Occup Environ Med 2008;65:438-45.

3 Karasek RA. Job demands, job decision latitude, and mental strain: Implications for job redesign. Admin Sci Qtrly 1979;24:285-307.

4 Kivimäki M, Nyberg ST, Batty GD, et al. Job strain as a risk factor for coronary heart disease: a collaborative meta-analysis of individual participant data. Lancet 2012;380:1491-7. 
5 Lloyd-Jones DM, Wang TJ, Leip EP, et al. Lifetime risk for development of atrial fibrillation: the Framingham Heart Study. Circulation 2004;110:1042-6.

6 Benjamin EJ, Chen PS, Bild DE, et al. Prevention of atrial fibrillation: report from a national heart, lung, and blood institute workshop. Circulation 2009;119:606-18.

7 Olsson LG, Swedberg K, Lappas G, et al. Trends in mortality after first hospitalization with atrial fibrillation diagnosis in Sweden 1987 to 2006. Int J Cardiol 2013;170:75-80.

8 Wilhelmsen L, Rosengren A, Lappas G. Hospitalizations for atrial fibrillation in the general male population: morbidity and risk factors. J Intern Med 2001;250:382-9.

9 Rosengren A, Hauptman PJ, Lappas G, et al. Big men and atrial fibrillation: Effects of body size and weight gain on risk of atrial fibrillation in men. Eur Heart $J$ 2009;30:1113-20.

10 Calvo N, Brugada J, Sitges $\mathrm{M}$, et al. Atrial fibrillation and atrial flutter in athletes. Br J Sports Med 2012;46(Suppl 1):37-43.

11 Eaker ED, Sullivan LM, Kelly-Hayes M, et al. Anger and hostility predict the development of atrial fibrillation in men in the Framingham Offspring Study. Circulation 2004;109:1267-71

12 Chen LY, Shen W-K. Epidemiology of atrial fibrillation: A current perspective. Heart Rhythm 2007;4:S1-6.

13 Wilhelmsen L, Berglund G, Elmfeldt D, et al. The multifactor primary prevention trial in Gothenburg, Sweden. Eur Heart J 1986;7:279-88.

14 Torén K, Schiöler L, Giang KW, et al. A longitudinal general-population based study of job strain and risk for coronary heart disease and stroke in Swedish men. BMJ Open 2014;4:e004355.

15 Arbetsmarknadsstyrelsen. Nordisk yrkesklassificering: Systematisk förteckning över yrkesområden, yrkesgrupper, yrkesfamiljer och individualyrken med kodnummer och definitioner. Stockholm, Sweden, 1974. [In Swedish].
16 Johnson JV, Stewart W, Hall EM, et al. Long-term psychosocial work environment and cardiovascular mortality among Swedish men. Am J Public Health 1996;86:324-31.

17 Fredlund P, Hallqvist J, Diderichsen F. Psykosocial yrkesexponeringsmatris. Arbete och Hälsa 2000;11:1-37 [In Swedish].

18 Giang WK, Björck L, Lappas G, et al. Stroke and coronary heart disease-Predictive power of standard risk factors until old age. Long term cumulative risk study among men in Gothenburg, Sweden. Eur Heart J 2013:34:1068-74.

19 Lin DY, Wei L-J, Ying Z. Checking the Cox model with cumulative sums of martingale-based residuals. Biometrika 1993;80:557-72.

20 Mikkelsen S, Bonde JP, Hviid Andersen J. Analysis of job strain effects. Occup Environ Med 2011;68:786.

21 Aldhoon B, Melenovsky V, Peichl P, et al. New insights into mechanisms of atrial fibrillation. Phsyiol Res 2010;59:1-12.

22 Kivimäki M, Nyberg ST, Fransson El, et al. Associations of job strain and lifestyle factors with risk of coronary artery disease: A meta-analysis of individual participant data. Can Med Assoc J 2013;185:763-9.

23 Tüchsen $F$, Hannerz $H$, Roepstorff $C$, et al. Stroke among professional drivers in Denmark, 1994-2003. Occup Environ Med 2006;63:456-60.

24 Karjalainen J, Kujula UM, Kaprio J, et al. Lone atrial fibrillation in vigorously exercising middle aged men: A case-control study. $\mathrm{Br} \mathrm{Med} \mathrm{J}$ 1998;316:1784-5.

25 Mont L, Tamborero D, Elosua R, et al. Physical activity, height, and left atrial size are independent risk factors for lone atrial fibrillation in middle-aged healthy individuals. Europace 2008;10:15-20.

26 Andersen K, Farahmand B, Ahlbom A, et al. Risk of arrhythmias in 52755 long-distance cross-country skiers: A cohort study. Eur Heart J 2013;34:3624-31. 